\title{
Stroke during Pregnancy and Puerperium in Young Females below the Age of 40 Years as a Result of Gerebral Venous/Venous Sinus Thrombosis
}

\author{
B. C. Bansal, M.D., * R. R. Gupta, M.D., ** \\ C. Prakash, M.D.***
}

SUMMARY

One hundred and thirty-eight cases of cerebral venous/venous sinus thrombosis during the puerperium have been studied. Maximum number of cases (112 cases) occurred in the age below 30 years. Signs and symptoms appeared in most of the cases ( 72 cases) during the first 7 days of post partum period. One hundred and eleven cases were multipara. Commonest signs and symptoms were fever (85 cases); headache (66 cases), convulsions (64 cases), altered consciousness (57 cases), hemiplegia ( 60 cases), papilloedema ( 48 cases), etc. Carotid angiography done in 55 cases revealed block in middle part of superior sagittal sinus in 24, and localised, dilated and tortuous cortical veins in 5. A statistically significant rise in serum triglycerides, phospholipids, free fatty acids, blood platelet count, platelet adhesive index, and fall in blood fibrinolytic activity were found as compared with normals. These factors may be playing a role in the etiology of cerebral venous/venous sinus thrombosis during puerperium.

Additional Indexing Words:

Cerebral angiography Cerebrovascular accident Stroke Venous thrombosis Puerperium Lipids Platelets Fibrinolytic activity

WEREBROVASCULAR accidents have been recognized for many years
as a hazard in young females during pregnancy and puerperium.
Meniere ${ }^{1)}$ was the first to demonstrate that cerebral venous catastrophes could
occur during pregnancy and puerperium and Abercrombie ${ }^{2)}$ published the
first case of puerperal venous sinus thrombosis with post mortem examination.
The risk of stroke during pregnancy and puerperium, however, did not re-
ceive much attention until Symonds, ${ }^{3)}$ Martin ${ }^{4}$, Martin and Sheehan, and
Stansfield ${ }^{5)}$ published their clinical and autopsy studies. In Western coun-
tries the disease is uncommon ${ }^{7-9)}$ but it is the commonest cause of strokes in

From the Department of Medicine, Medical College, Rohtak, Haryana, India.

* Professor of Medicine

* Lecturer in Medicine

*** Professor of Medicine

Received for publication May 25, 1979. 
young females in India. ${ }^{10)-181}$

In India the incidence of primary cerebral venous sinus thrombosis is around 4.5 per 1,000 obstetric admissions ${ }^{17)}$ as compared with Western incidence of 1 per 1,666 to 1 per 10,000 pregnancies. ${ }^{19)-22}$ In India about $25 \%$ of maternal deaths related to child bearing occur as a result of cerebrovascular accidents. ${ }^{17)}$ The etiology and pathogenesis of the increased tendency to cerebral venous sinus thrombosis during pregnancy and puerperium are still not clear. Various mechanisms have been postulated for its occurrence viz. retrograde spread from pelvic veins via vertebral veins during uterine contractions, ${ }^{23}$ damage to the superior sagittal sinus due to fluctuations in the intracranial pressure during delivery, ${ }^{24}$ and an increased thrombotic tendency because of changes in various coagulation factors. ${ }^{18), 24)-28}$, All these theories, however, do not explain the occurrence of the disease in the 2nd and 3rd trimester of pregnancy on the one hand and in the second week of puerperium on the other.

\section{Material and Methods}

One hundred and thirty-eight cases who developed cerebral venous/venous sinus thrombosis during pregnancy and puerperium were studied. The diagnosis was mainly clinical, based on the established criteria. ${ }^{29), 30)}$ A detailed history, thorough physical and neurological examinations were recorded on a special proforma. In all cases eclampsia, pre-eclamptic toxemia, albuminuria, hypertension or oedema, metabolic causes of coma and convulsions, moningeal infection, and intracranial neoplasms were excluded by appropriate investigations.

The following routine investigations were done in each patient (hemoglobin, total leucocyte count, differential leucocyte count, erythrocyte sedimentation rate); urine and stool examination; blood urea; blood sugar; blood for V.D.R.L.; electrocardiogram; X ray skull; cerebrospinal fluid (C.S.F.) examination for cytology, biochemistry, and V.D.R.L. The following parameters were specially studied, serum triglycerides ${ }^{31)}$; serum phospholipids ${ }^{32)}$; serum free fatty acids ${ }^{331}$; serum lipoproteins ${ }^{34)}$; blood fibrinolytic activity ${ }^{35)}$ measuring combined plasminogen activator and plasmin activity on fibrin plates containing plasminogen with plasma of patients; platelet adhesive index and adhesive platelets. ${ }^{36)}$ A contralateral percutaneous common carotid angiography was also done well below the bifurcation in the neck with serial pictures in anteroposterior \& lateral views whenever possible. All these investigations with the exception of the radiological investigation were also done in the following groups to serve as controls for comparison:

Group A: 25 non-pregnant healthy women of child bearing age;

Group B: 25 healthy pregnant women nearing term;

Group C: 25 women in the first week of normal puerperium after 48 hours of delivery.

Three cases of arterial occlusion seen during this study were analysed separately. 


\section{OBservations}

Age: One hundred and twelve cases were below the age of 30 years (15-20 years 22 cases; $21-30$ years 90 cases). No case was seen above the age of 40 years ( $31-40$ years 26 cases).

Parity: Cerebral venous/venous sinus thrombosis was commonly seen in multipara (111 cases). Only 27 cases were primipara. Delivery was of full term and normal in all cases. There was neither any evidence of premature or post mature delivery nor excessive bleeding. In all these cases delivery was conducted at home by an untrained nurse under inadequate

Table I. Clinical Features in 138 Cases

\begin{tabular}{|c|c|}
\hline Name of symptoms and sign & No. of cases \\
\hline Fever & 85 \\
\hline Headache & 66 \\
\hline Convulsion-generalised & 40 \\
\hline- focal & 24 \\
\hline Unconsciousness & 57 \\
\hline Vomiting & 49 \\
\hline Giddiness & 6 \\
\hline Paresthesia & 5 \\
\hline Irrelevant talk & 5 \\
\hline Vertigo & 2 \\
\hline Diplopia & 2 \\
\hline Severe pain in paralysed limb & 2 \\
\hline Blurred vision & 1 \\
\hline Excessive salivation & 1 \\
\hline \multicolumn{2}{|l|}{ Focal neurological deficit } \\
\hline Complete hemiplegia & 60 \\
\hline Papilloedema & 48 \\
\hline Motor aphasia & 35 \\
\hline Paraplegia with incontinence of urine and faeces & 29 \\
\hline Quadriplegia & 12 \\
\hline Isolated supranuclear 7 th nerve palsy & 12 \\
\hline Monoplegia & 7 \\
\hline Hemiplegia with visceral involvement & 3 \\
\hline Sixth nerve palsy & 2 \\
\hline Hemianesthesia, cortical type & 2 \\
\hline \multicolumn{2}{|l|}{ Others } \\
\hline Neck regidity & 4 \\
\hline Oedema eyes & 2 \\
\hline Thrombophlebitis legs & 1 \\
\hline
\end{tabular}


asepsis.

Time of onset of symptoms: More than half of the cases (72 cases) were within first 7 days, 44 cases between 8-14 days, and 21 cases after 14 days of the delivery. Only 1 patient developed cerebral venous/venous sinus thrombosis in the third trimester of pregnancy.

Clinical features: Clinical features are summarised in Table 1. Headache was mostly unilateral limited either to the forehead or temple and was severe and persistent in 16 cases. Jacksonian seizure with a spreading tendency occurred in 5 cases. One case developed status epilepticus. Four patients presensted with symptoms of raised intracranial pressure consisting of headache, vomiting, coma, papilloedema, and neck stiffness. Puerperal scpsis was seen in 4 cases only. Three patients developed terminal uraemia.

Cerebrospinal fuid (C.S.F.): Lumbar puncture was done in 97 cases. Detailed findings are shown in Table II. A raised C.S.F. pressure was the most frequent finding (80 cases). Red blood cells were seen in 10 cases. Proteins were raised in 34 cases $(34.9 \%$ ) of which 8 cases had protein of more than $250 \mathrm{mg} \%$ and all depicted xanthochromia. V.D.R.L. was negative in all the cases. No change in sugar or chloride was seen.

Cerebral angiography: Carotid angiography was possible in 55 cases only.

Table II. Cases C.S.F. Findings in 97

\begin{tabular}{|c|c|c|}
\hline & \multicolumn{2}{|c|}{ No. of cases } \\
\hline Raised pressure & 80 & \\
\hline Xanthochromia & 8 & \\
\hline M/E R.B.C. & 10 & \\
\hline W.B.C. & 10 & \\
\hline \multicolumn{3}{|l|}{ Protein } \\
\hline $20-40 \mathrm{mgm} \%$ & 63 & $(65.1 \%)$ \\
\hline $41-100 \mathrm{mgm} \%$ & 22 & $(22.6 \%)$ \\
\hline$>100 \mathrm{mgm} \%$ & 12 & $(12.3 \%)$ \\
\hline
\end{tabular}

Table III. Angiographic Findings in 55 Cases

\begin{tabular}{l|c}
\hline \multicolumn{1}{c|}{ Type of lesion } & No. of cases \\
\hline Normal arterial phase & 55 \\
Middle part of superior sagittal sinus not seen & 24 \\
Localized dilated tortuous cortical veins & 5 \\
Club shaped sinus deformity & 1
\end{tabular}


Table VI. Serum Lipids in 50 Cases of Cerebral Venous Sinus Thrombosis and Controls

\begin{tabular}{|c|c|c|c|c|c|c|}
\hline \multirow{2}{*}{ Group } & \multirow{2}{*}{$\begin{array}{l}\text { S. trigly- } \\
\text { cerides. } \\
\text { (mg\%) }\end{array}$} & \multirow{2}{*}{$\begin{array}{l}\text { S. Phospho- } \\
\text { lipids } \\
(\mathrm{mgm} \%)\end{array}$} & \multirow{2}{*}{$\begin{array}{l}\text { Serum free } \\
\text { fatty acids } \\
(\mathrm{mg} \%)\end{array}$} & \multicolumn{3}{|c|}{ Lipoproteins $(\%)$} \\
\hline & & & & Beta & Pre-beta & Alpha \\
\hline A. Non-pregnant & $103 \pm 20.95$ & $231 \pm 64.72$ & $547 \pm 176.07$ & $54 \pm 6.01$ & $30 \pm 3.26$ & $17 \pm 5.44$ \\
\hline B. Healthy pregnant & $105 \pm 19.47$ & $283 \pm 69.29$ & $600 \pm 309.22$ & $61 \pm 9.41$ & $26 \pm 3.09$ & $14 \pm 4.23$ \\
\hline C. Normal puerperium & $124 \pm 33.62$ & $299 \pm 89.88$ & $912 \pm 375.99$ & $60 \pm 8.49$ & $27 \pm 4.95$ & $13 \pm 4.73$ \\
\hline $\begin{array}{l}\text { D. Ceberal venous } \\
\text { sinus thrombosis }\end{array}$ & $153 \pm 51.6$ & $292 \pm 58.4$ & $763 \pm 329.09$ & $58 \pm 7.75$ & $27 \pm 4.43$ & $15 \pm 5.40$ \\
\hline
\end{tabular}

Table V. Blood Fibrinolytic Activity in 19 Clases of Cerebral Venous Sinus Thrombosis and Controls

\begin{tabular}{l|c}
\multicolumn{1}{c|}{ Group } & $\begin{array}{c}\text { Blood fibrinolytic activity lysis zone } \\
\left(\mathrm{mm}^{2}\right)\end{array}$ \\
\hline A. Non pregnant & $391 \pm$ S.D. 158.69 \\
B. Healthy pregnant & $467 \pm$ S.D. 170.55 \\
C. Normal puerperium & $347 \pm$ S.D. 125.77 \\
D. Cerebral venous sinus thrombosis & $253 \pm$ S.D. 70.78
\end{tabular}

The arterial phase was normal in all the cases. Detailed findings are shown in Table III.

Prognosis: Out of a total of 138 cases only 38 cases $(27.5 \%)$ died while $100(72.5 \%)$ cases recovered completely.

Serum lipids: There was a rise in almost all the lipid fractions in cases of cerebral venous/venous sinus thrombosis (Group D) as compared with nonpregnant women (Group A) and women who had a normal puerperium (Group $\mathrm{G}$ ). This rise was statistically significant $(\mathrm{p}<0.001)$ in respect to serum triglycerides, phospholipids and free fatty acids (Table IV).

Blood fibrinolytic activity: There was a fall of blood fibrinolytic activity in cases of Group C and in cases of cerebral vonous sinus thrombosis (Group D). The fall in cases of cerebral venous sinus thrombosis has been found to be statistically significant $(\mathrm{p}<0.001)$ in comparison with Group A and Group C patients (Table V).

Platelet adhesiveness: Platelet adhesive index and absolute number of adhesive platelets were higher in Group B patients, Group $\mathrm{C}$ patients and in cases of cerebral venous/venous sinus thrombosis (Group D) as compared with Group A patients, but the results were much higher in cases of cerebral 
Table VI. Platelet Function Tests in 25 Cases of Cerebral Venous Sinus Thrombosis and Controls

\begin{tabular}{l|c|c}
\hline \multicolumn{1}{c|}{ Group } & Platelet adhesive index & $\begin{array}{c}\text { Platelet adhesive number } \\
\text { (per cmm) }\end{array}$ \\
\hline A. Non pregnant & $1.05 \pm$ S.D. 0.05 & $502.40 \pm$ S.D. 5195 \\
B. Healthy pregnant & $1.10 \pm$ S.D. 0.06 & $540.00 \pm$ S.D. 2093 \\
C. Normal puerperium & $1.20 \pm$ S.D. 0.089 & $645.00 \pm$ S.D. 8230 \\
D. Cerebral venous sinus thrombosis & $1.35 \pm$ S.D. 0.11 & $718.00 \pm$ S.D. 3830
\end{tabular}

Table VII. Statistical Analysis of Cases of Cerebral Venous Sinus Thrombosis as Compared with Normal Delivery Cases

\begin{tabular}{|c|c|c|c|}
\hline & Group & $\begin{array}{l}\text { Platelet adhesive } \\
\text { index }\end{array}$ & $\begin{array}{l}\text { Adhesive platelets } \\
\text { (1 cmm })\end{array}$ \\
\hline C. & Normal puerperium & 1.20 & 64.600 \\
\hline & Cerebral venous/venous sinus thrombosis & 1.35 & 71.500 \\
\hline & Difference & 0.15 & 7.200 \\
\hline & ' $t$ ' value* & 5.4 & 36.4 \\
\hline
\end{tabular}

* ' $t$ ' value from the table for $48^{\circ}$ freedom at $5 \%$ level of significance is 2.01 . So values higher than 2.01 are statistically significant.

venous/venous sinus thrombosis than in any other group (Table VI and VII).

Leucocytosis was seen in 10 cases. It probably does not indicate infection but reflects the thrombotic process itself. One hundred and one $(89.9 \%)$ cases had a hemoglobin of less than $10 \mathrm{Gm} \%$. Only $12(11.1 \%)$ cases had hemoglobin between $10-13 \mathrm{Gm} \%$.

Arterial thrombosis: All the 3 cases of arterial thrombosis were conscious with complete hemiplegia, without seizures and papilloedema, normal C.S.F. and showed no improvement of the neurological deficit. Two cases showed extracranial internal carotid artery block in the neck and 1 case had middle cerebral artery block.

\section{Discussion}

In India majority of patients with cerebral strokes associated with pregnancy and the puerperium have cerebral venous/venous sinus thrombosis, ${ }^{11)-13(17), 18,, 21), 30), 37)-41}$ On the other hand Cross et al ${ }^{8}$ have reported over $70 \%$ of these strokes as being due to occlusive cerebral arterial disease or ischaemic lesions unrelated to thrombosis of the intracranial venous system. Others have also considered cerebral venous thrombosis as a rare complica- 
tion. ${ }^{7,91,291,42,43)}$ In India cerebral arterial occlusion is far less common and was proven in $47(15.6 \%)$ out of a total of 301 patients reported. ${ }^{13), 14), 17), 38), 44 \text { ) }}$ In this study only $3(2 \%)$ of our patients had arterial occlusion. Dashpande $^{37}$ described the post mortem findings in 7 cases of cerebral venous sinus thrombosis and Banerjee et $\mathrm{al}^{411}$ in 8 fatal cases seen over a period of 2 years of cerebral venous sinus thrombosis out of a total of 24 patients.

The diagnosis of cerebral venous sinus thrombosis is mainly clinical. The clinical picture of venous occlusion is often diagnostic. In arterial occlusion patients are usually conscious, seizures are rare, there is dense hemiparesis, papilloedema is absent, the G.S.F. is normal, neurological deficit persists, positive angiographic findings are more common and the prognosis for life is good, but on the other hand in cerebral venous sinus thrombosis, the mortality is high, deterioration in the level of consciousness is high, convulsions are common and those who survive have very little disability. Cerebral venous/venous sinus thrombosis should always be suspected in a previously healthy woman developing a triad, of varying degrees of paresis, headache, and convulsions after delivery. ${ }^{24), 29,30,}$ The percentage of various clinical features associated with cerebral venous/venous sinus thrombosis during pregnancy and the puerperium vary because the development of these symptoms depends on the site and extent of the thrombosis of the sinuses, cortical veins or deep veins and the potentialities of the collateral circulation.

Headache occurred in 66 of our cases and may precede the other symptoms by several hours or days. ${ }^{30,43), 45), 46}$, The intensity of the headache parallels the severity of the cerebral lesions and is mostly unilateral, limited either to the forehead, temple or occiput or may be diffuse ${ }^{46}$ but is severe and persistent. Headache is not necessarily due to raised intracranial pressure but is probably primarily caused by direct involvement of pain sensitive dural sinuses by thrombophlebitis. ${ }^{47}$ Convulsions may be generalized or focal ${ }^{29}$ ) but are most often the former. ${ }^{17,301,44)}$ They were seen in 64 cases in this series, being generalised in 40 and focal in 24 cases. Jacksonian seizures were seen in 5 cases and had a spreading tendency. Similar observations have also been made by other workers. ${ }^{48)}$ Adversive seizures or status epilepticus have been recorded in the literature, ${ }^{17}$ ) but were seen only in 1 case in this study. These are due to local cortical irritation caused by cerebral oedema, hemorrhage or venous engorgement and may be followed by paralysis within a few days.

All degrees of mono or hemiparesis, crossed hemiparalysis of face and limbs with or without sensory disturbances, speech defects and visual disturbances can occur. ${ }^{45}$ ) Hemiplegia which may be accompanied with varying degree of sensory and motor aphasia. ${ }^{11), 17), 21,301,38,44), 47)}$ is the commonest 
feature and was seen in 60 cases. Paraplegia with normal upper limbs and incontinence of urine and stools which occurs due to involvement of both para sagittal regions by the thrombosis ${ }^{49}$ was seen in 29 cases. Cortical anaesthesia seen in 2 cases without hemiplegia and aphasia has also been reported. ${ }^{50}$ )

Less commonly a syndrome of raised intracranial pressure consisting of headache, nausea, vomiting, photophobia, coma, papilloedema, neck stiffness, and raised C.S.F. pressure can occur due to sagittal sinus thrombosis. ${ }^{171,26), 47), 51)}$ Four patients were seen with such a syndrome. Papilloedema and signs of raised tension can occur in cerebral venous sinus thrombo$\operatorname{sis}^{291,43), 44), 52)}$ and were seen in 48 of our patients. The meningitic picture seen in these cases is due to hemorrhagic infarction and subarachnoid hemorrhage $^{17 /}$ and was seen in 4 of our cases. Pyrexia found in 85 cases despite lack of evidence of active infection probably reflects the thrombotic process. It was also seen by other workers. ${ }^{17,21), 291,44), 47)}$ Sixth nerve palsy, seen in 2 cases in this series of cerebral venous sinus thrombosis, occurs due to thrombosis of the inferior petrosal sinus or severe venous stasis or upwards or downward displacement of the nerve due to swelling of the cerebral hemispheres. ${ }^{53}$ ) Paralysis of the $3 \mathrm{rd}$, 5th or 6 th nerve can also occur due to thrombosis of the cavernous sinus ${ }^{54)}$ and extension of the thrombosis from the cavernous to the superior petrosal sinus can cause paralysis of the 5 th nerve followed by 9 th, 10th, and 11 th cranial nerves. ${ }^{53}$ ) Thrombosis of the superior sagittal sinuses is sometimes associated with proptosis of the eyes without involvement of cavernous sinus ${ }^{55,56)}$ and occurred in 2 of our patients. Other less common clinical features include cortical blindness, persistent hypotenison, postural hypotension, hypothermia, hypoglycemia with sweating associated with clinical akinetic mutism (alert but inert) probably due to ischaemia of hypothalmic area secondary to puerperal cerebral deep vein thrombosis. ${ }^{17}$ Fluctuating or sustained hypertension can also occur ${ }^{21,38), 47)}$ due to reflex response designed to overcome increased cerebrovascular resistance as a result of increased intracranial pressure. ${ }^{57)}$

Examination of the C.S.F. is of little advantage for the diagnosis of cerebral venous/venous sinus thrombosis. Characteristic features of xanthochromia, markedly raised protein and varying degrees of R.B.C. and W.B.C. were seen in 10 cases, probebly due to spread of thrombosis to the cortical veins, ${ }^{29), 52), 58)}$

Earlier attempts to demonstrate occlusion of the major dural sinuses were made by sinography. ${ }^{59-62)}$ The importance of cerebral angiography was stressed by Krayenbuhl ${ }^{63}$ ) and Weber $^{52}$ ) and they considered that a deficiency in the venous phase of angiogram could be diagnostic of primary 
cortical vein occlusion. Occasionally the arterial phase may show displacement as a consequence of cerebral edema or infarction in the involved hemisphere, which may become normal when repeated after 3-4 weeks. ${ }^{17}$ Certain abnormalities of the venous phase suggest a sagittal sinus thrombosis. ${ }^{20)}$ The middle part of the superior sagittal sinus was not seen in 14 cases and localized tortousity of the cortical veins and a club shaped deformity of the sinus was seen in 5 and in 1 case, respectively. Failure to obtain filling of the basal sinus is a bad prognostic sign. Other abnormalities of venous phase suggestive of cerebral venous sinus thrombosis are:

i) Slowing of the circulation which is almost a constant feature;

ii) Cork screw vessels which do not reach the cortical surface ${ }^{63), 64)}$;

iii) Failure to fill draining superficial cerebral veins in a circumscribed area of the brain in the relevant hemisphere and related to the patients' physical signs. This can be confirmed by comparison with the healthy side;

iv) Failure to demonstrate all or part of a sinus or localised irregularity of the lumen ${ }^{43)}$;

v) Wide filling of the inferior sagittal sinus and internal cerebral vein along with failure in filling of the superior sagittal sinus. ${ }^{29}$ )

Of the various theories postulated for the occurrence of cerebral venous/ venous sinus thrombosis one of the principal ones has been a hypercoagulate state. ${ }^{25)}$ This hypercoagulate state is due to increase of factors VII and $\mathrm{X}^{27}$, hypophospholipemia, ${ }^{65)}$ hyperlipemia, increased platelet adhesiveness, ${ }^{28}$ ) hyperfibrinogenemia, ${ }^{66)}$ and decreased fibrinolysis. ${ }^{66), 67)}$ A $30 \%$ rise in platelets has been demonstrated during puerperium ${ }^{68)}$ and this rise is even higher if a severe post partum hemorrhage occurs. ${ }^{69)}$ Peak increase in platelets occurs about the 10 th post partum day, ${ }^{25)}$ the time when venous thrombosis usually occurs. ${ }^{68)}$ In addition, there occurs increased platelet stickiness during pregnancy and the puerperium. ${ }^{25), 28)}$ In this series levels of platelet adhesive index and absolute number of adhesive platelets were higher during pregnancy and the puerperium as compared with non pregnant controls. A rise in serum lipids occurs during pregnancy and this rise continues even during the puerperium ${ }^{28), 70)-74)}$ irrespective of the socio-economic status and diet taken. ${ }^{74}$ A statistically significant rise in serum triglycerides, phospholipids, free fatty acids and increase in platelet adhesiveness as well as absolute number of adhesive platelets found in this study have also been reported by other workers. ${ }^{17), 28)}$ Increased platelet aggregation can occur not only with high serum levels of fatty acids, ${ }^{75)}$ but can also be induced by long chain fatty acids in experimental models. ${ }^{76), 77)}$ A rise in beta and prebeta lipoproteins occurs in cerebral venous sinus thrombosis ${ }^{44)}{ }^{78}$ and the affinity between platelets and certain lipoproteins has also been stressed. ${ }^{79}$ ) 
Plasma fibrinogen levels rise during pregnancy 25, ,70),75),80) which may increase by $50 \%$ in the last trimester ${ }^{81}$ ) and remain elevated during the puerperium. ${ }^{13), 66)}$ Increased values of fibrinogen occur in cerebral venous sinus thrombosis ${ }^{44}$ and the progressive rise in serial estimations is a useful warning sign of its progression. ${ }^{17}$ )

In addition, there is evidence that fibrinolysins are reduced during pregnancy and the puerperium. ${ }^{66), 67)}$ A statistically significant fall in fibrinolytic activity was seen in cases of cerebral venous sinus thrombosis as compared with normal puerperium.

This increased coagulability may be playing a role in the etiology of cerebral venous/venous sinus thrombosis occurring during the purperium in young females below the age of 40 years.

\section{REFERENCES}

1. Meniere P: Obscrvations ct reflcxious sur I' hemorrhagie cerebrale consideree. Pendant la prossesse pendant et apres I'accouchement. Archives of General Medicine 16: 489, 1828.

2. Abercrombie J: Pathological and Practical Researches on Diseases of the Brain and Spinal Cord. Edinburgh, p83, 1828

3. Symonds CP: Cerebral thrombophlebitis. Brit Med J 2: 348, 1940

4. Martin JP, Sheehan HL: Primary thrombosis of cerebral veins following child birth. Brit Med J 1: 349,1941

5. Martin JP: Thrombosis in the superior longitudinal sinus following child birth. Brit Med J 2: 537,1941

6. Stansfield FR: Puerperal cerebral thrombophlebitis treated by heparin. Brit Med J $\mathbf{1}$ : 436,1942

7. Jennett WB, Cross JN: Influence of pregnancy and oral contraception on the incidence of strokes in women of child-bearing age. Lancet 1: 1019, 1967

8. Cross JN, Castro PO, Jennett WB: Cerebral strokes associated with pregnancy and the puerperium. Brit Med J 3: 214, 1968

9. Barnes CG: Medical Disorders in Obstetric Practice. Blackwell Scientific Publications, $\mathrm{p} 220,1970$

10. Padmavati S, Gupta S, Singh B: A clinical study of 44 cases of hemiplegia in adult women. Neurology (India) 5: 59, 1957

11. Parkash C, Singh S: Cerebral venous and sinus thrombosis in puerperium. Journal of Association of Physicians of India 8: 363, 1960

12. Singh B, Padmavati S, Pathak SN: Encephalopathies in pregnancy and the puerperium. A study of 36 cases. Neurology (India) 9:1, 1961

13. Janaki S, Thomas L: Neurological complications occurring during pregnancy and puerperium. Neurology (India) 11: 128, 1963

14. Pathak SN, Dhar P, Berry K, Kumar S: Venous and arterial thrombosis in 30 young Indian women. Neurology (India) 14: 102, 1966

15. Abraham J, Rao PSS, Inbaraj SG, Shetty G, Jose GJ : An epidemiological study of hemiplegia due to stroke in South India. Stroke 1: 477, 1970.

16. Lorincz AB, Moore RY: Puerperal cerebral venous thrombosis. Am J Obstetric Gynaecol 83: 311,1962

17. Srinivasan $\mathrm{K}$, Natarajan $\mathrm{M}$ : Cerebral venous and arterial thrombosis in pregnancy and puerperium. Neurology (India) 22: 131, 1974 
18. Bansal BC, Prakash C, Gupta, RR, Brahmanandam KRV: Study of serum lipid and blood fibrinolytic activity in cases of cerebral venous/venous sinus thrombosis during the puerperium. Am J Obstetric Gynaecol 119: 1079, 1974

19. Koller T, Stamm H, Hauser GA, Klingler M: Die zerebralen Venen- und Sinusthrombosen in der Geburtshilfe. Thrombosiset Diathesis Haemorrhagica (Stuttg) 1, 37, 1957

20. Huggenberg HR, Kesselring R: Post partuale cerebrale Komplikationen. Gynaecologica (Basal) 146: 312, 1958

21. Jolly SS, Rai B, Singh N: Cerebral venous sinus thrombosis in puerperium. Jonural of Association of Physicians of India 19: 447, 1971

22. Goldman JA, Echerling B, Gans B: Intracranial venous sinus thrombois in pregnancy and puerperium. Journal of Obstetrics and Gynaecology British Common Wealth 71 : 791, 1964

23. Batson OV: The function on the vertebral veins and their role in the spread of metastases. Annals of Surgery 112: 138, 1940

24. Kandall D: Thrombosis of intracranial veins. Brain 71: 386, 1948

25. Wright HP: Changes in adhesiveness of blood platelets following parturition and surgical operations. J Pathol Bacteriol 54: 461, 1942

26. Garcin R, Pestel M: Thrombophlebites cerebrales. XXX ${ }^{\circ}$ Congress of France de Medicine, Algiers, p503, 1955

27. Pechest L, Alexander B: Increased clotting factors in pregnancy. New Engl J Med 265: 1093,1961

28. Prakash $\mathrm{C}$, Arya KK, Singla KP, Bansal BC: Study of platelet adhesiveness and serum lipids in cerebral venous/venous sinus thrombosis during puerperium. Journal of Association of Physicians of India 18: 815, 1970

29. Carroll JD, Leak D, Lee HA: Cerebral thrombophlebitis in pregnancy and the puerperium. Quarterly Journal of Medicine 35: 347, 1966

30. Amias AG: Cercbral vascular disease in pregnancy, 2-occlusion. Journal of Obstetrics and Gynaecology British Common Wealth 77: 312, 1970

31. Van Handel E, Zilversmith DB, Bowman K: Micromethod for direct determination of serum triglycerides, J Lab Clin Med 50: 152, 1957

32. Zilversmith DB, Davis, AK: Micro-determination of plasma phospholipids by trichloroacetic acid precipitation. J Lab Clin Med 35: 155, 1950

33. Novak M: Calorimetric ultra-micromethod for determination of free fatty acids. J Lipid Res 6, 431, 1965

34. Robert S, Fredreac T: Sharper separation of lipoproteins species by paper electro-phoresis in albumin containing buffer. J Lab Clin Med 61 : 518, 1963

35. Astrup T, Mullertz SS: Fibrin plate method for estimating fibrinolytic activity. Archiv Biochem 40: 346, 1952

36. Moolten SE, Vreman L: The adhesiveness of blood platelets in thromboembolism and haemorrhagic disorders. Am J Clin Pathol 19: 701, 1949

37. Deshpande DH: Puerperal intracranial venous thrombosis. Neurology (India) 15: 164, 1967

38. Agarwal K: Neurological disorders complicating normal pregnancy and puerperium. Journal of the Association of Physicians of India 16: 645, 1968

39. Srinivasan, $\mathrm{K}$ and Ramamurthi B: Neurological disorders in pregnancy and puerperium. Journal of Association of Physicians of India 19: 705, 1971

40. Bansal BC, Prakash C, Jain AL, Brahamanandam KRV: Cerebrovascular disease in young individuals below the age of 40 years. Neurology (India) 21: 11, 1973

41. Banerjee AK, Chopra JS, Sawhney BB: Postpartum cerebral venous thrombosis. Study of autopsy material. Neurology (India) 21: 19, 1973.

42. Humphrey JC, Newton TH: Internal carotid artery occlusion in young adults. Brain 83 : 865,1960

43. Kalbag RM, Woolf AL: Cerebral Venous Thrombosis. Oxford Medical Publications, London, p156, 1967 
44. Bhaskar PA: Strokes in woman related to pregnancy and puerperium. Personal Communication, 1976

45. Harvieux E: Traite Clinique et Pratique des Maladies Puerperales. Paris, p771, 1870

46. Dubois J: Les thrombo-phlebites cerebrales du postpartum. Gynaecologie et Obstetrique 55: 472,1956

47. Biback SM, Franklin A, Stata W: Puerperal hemiplegia. Am J Obstetric Gynaecol 84: 45,1962

48. Biemond A: Clinical symptoms of so-called spontaneous thrombosis of superior longitudinal sinus. Nederlandse Tijdschrift voor (Geneeskunde) 79: 5422, 1935

49. Wilson G: Crural monoplegia and paraplegia of cortical origin with a discussion of the cortical centres for the rectum, bladder and sexual functions. Archives of Neurology and Psychiatry (Chic) 10:669, 1923

50. King AB: Neurologic conditions occurring as complications of pregnancy. Archives of Neurology and Psychiatry (Chic) 63: 471, 1950

51. Huhn A: Die Differential Diagnose der Hirnvenen- und Sinusthrombose. Acta Neurochirurigica (Wien) 7 (suppl): 355,1961

52. Weber G: Zerebrale Venen- und Sinus-Thrombosen. Schweiz-Archives of Neurology and Psychiatry chiat 82: 320,1958

53. Symonds CP: Intracranial thrombophlebitis. Otolaryngology lecture. Annals of Royal College of Surgeons (England) 10: 347, 1952

54. Milligan W: Septic sinus thrombosis its diagnosis and treatment. J Laryngol 38: 9, 1923

55. Kronig B: Uber sinen Fall autochthoner Sinusthrombose Inang. Diss. Nunich, 1889

56. Von Dusch T: On Thrombosis of the Cerebral Sinus. The New Sydenham Society, London, 1861

57. Ammermar HH, Stevens H: Intracranial venous thrombosis in early pregnancy. Am J Obstetric Gynaecol 78: 104, 1959

58. Symonds CP: Hydrocephalic and focal cerebral symptoms in relation to thrombo-phlebitis of dural sinuses and cerebral veins. Brain 60:531, 1937

59. Frenckner P: Sinography. Method of radiography in diagnosis of sinus thrombosis. J Laryngol 52: 350, 1937

60. Frenckner P: Sinography. Method of radiography in diagnosis of thrombosis. Acta Otolaryngologica (Stockh) 26: 441, 1937

61. Fishgold $H$, David $M$, Talairach J, Bregeat $P$ : Direct opacifying injections into the venous system of the head. Acta Radiologica 40: 128, 1953

62. Kinal ME, Jaegger RM: Thrombophlebitis of dural venous sinuses following otitis media. J Neurosurg 17: 81, 1960

63. Krayenbuhl $\mathrm{H}$ : Cerebral venous thrombosis, diagnostic value of cerebral angiography. Schweiz Archives of Neurology and Psychiatry 74: 261, 1954

64. Krayenbuhl H: Cerebral venous and sinus thrombosis. Clin Neurosurg 14: 1, 1967

65. Russ EM, Eder HA, Barr DP: Protein lipid rclationship in human plasma in prcgnancy and newborn. J Clin Invest 33: 1662, 1954

66. Gillman T, Naidoo SS, Hathorn M: Plasma fibrinogen activity in pregnancy. Lancet 2: 70,1959

67. Bonnar J, Mcnicol GP, Douglas AJ: Fibrinolytic enzyme system and pregnancy. Brit Med J 3: 387, 1969

68. Dawbarn RY, Earlam F, Evans WH: The relation of the blood platelets to thrombosis after operation and parturition. J Pathol Bacteriol 31: 833, 1928

69. Bland PB, Goldstein L: Coagulability of blood in pregnancy. Am J Obstetric Gynaecol 23: 815, 1932

70. Dieckman WJ, Wegner CR: Studies of blood in normal pregnancy, Arch Intern Med 53: 540,1934

71. Schwarz OH: Blood lipids in pregnancy. Am J Obstetric Gynaecol 39: 203, 1940

72. Peters JP, Man EB: The interrelations of serum lipids in normal persons. J Clini Invest 
22: 707,1943

73. DeAlvarez RR, Gaiser DP, Simkins DM, Smith EK, Bratvold GE: Serial studies of serum lipids in normal pregnancy. Am J Obstetric Gynaecol 77: 743, 1959

74. Mullick S, Bagga, OP, Mullick VD: Serum lipid studies in pregnancy. Am J Obstetric Gynaecol 89: 766, 1964.

75. Mustard JF, Murphy EA, Rowsell HC, Downie HG: Factors influencing thrombus formation in vivo. Am J Med 33: 6211962

76. Haslam RJ: Role of adenosine diphosphate in the aggregation of human blood platelets by thrombin and by fatty acids. Nature 202: 765, 1964

77. Kerr JW, Pirrie R, Macnlay I, Bronte-Stewart B: Platelet aggregation by phospholipids and free fatty acid. Lancet 1: 1296, 1964.

78. Pearce J, Aziz H: Uric acid and plasma lipids in cerebrovascular disease. Part-II. Uric acid plasma lipid, correlations. Journal of Neurology Neurosurgery and Psychiatry 33: 88, 1970

79. Housom -: The effect of human chylomicron suspensions on the recalcifications time of platelet-poor plasma. An effect due to blood platelets. Scand J Clin Lab Invest 13: 619, 1961

80. Stevens H, Ammerman HH: Intracranial venous thrombosis in early pregnancy. Am J Obstetric Gynaecol 78: 104, 1959

81. Sinclair MAM: On puerperal aphasia with an analysis of 18 cases. Lancet 2: 204, 1902 